\section{Modification of a Soil Percolation Apparatus for Soils of a High Organic Matter Content}

DURING recent investigations of a number of soils the percolation method introduced by Schloesing and Müntz ${ }^{1}$ was employed. The apparatus used was similar to that devised by Audus ${ }^{2}$, as modified and described by Chase?

It was found that the reacting solution did not percolate through soils of a high organic matter content after the first few minutes, even when sterile sand, or glass beads, or glass-wool had been mixed with the soil. It was apparent that a further modification of the apparatus was required to obtain adequate percolation with soils of this nature.

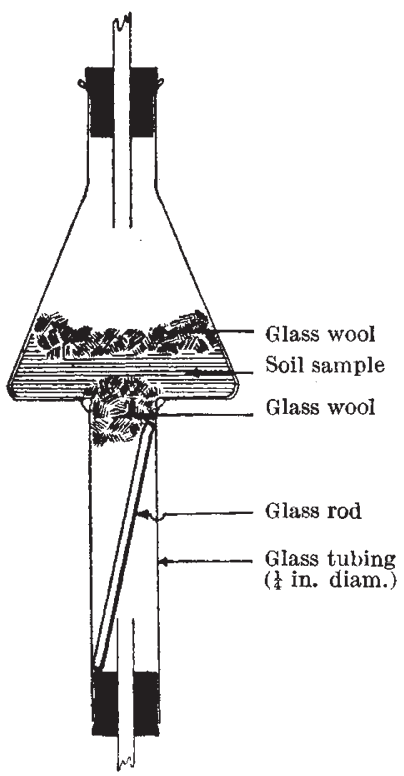

In order to permit the expansion of the soil during percolation the straight glass column was replaced by the apparatus shown in the accompanying diagram. A hole was blown in the bottom of an Erlenmeyer flask of $125-\mathrm{ml}$, capacity. A short length of $1 \frac{1}{4}$-in. diameter glass tubing was sealed to the opening thus made. A pad of glass wool was inserted into this tube so as to protrude slightly into the flask; it was held in position by a suitable length of glass rod. The soil sample was placed in the flask and covered by a pad of glass wool to prevent excessive disturbance of the soil by the impact of the drops of the percolating fluid.

This alteration in the shape of the column used for containing the soil has permitted the investigation of soils which could not previously be studied by this method.

One of the authors (T. M. B. P.) wishes to express his thanks to the National Research Council of Canada for the award of a scholarship and permission to publish this note.

T. M. B. PAYNE

P. H. H. GRAY

Department of Agricultural Bacteriology,

Macdonald College, McGill University. March 1.

${ }^{1}$ Schloesing, T., and Müntz, A., C.R. Acad. Sci., 84, 301 (1877).

2 Audus, L. J., Nature, 158, 419 (1946).

"Chase, F. E., Sci. Agric., 28, 315 (1948).

\section{Colour Change in the Echinoid, Diadema antillarum, Philippi}

PI YSIOLOGICAL colour change has been but rarely reported in echinoderms ${ }^{2}$. Mortensen ${ }^{2}$, in a footnote, makes cautious reference to the possibility of such changes occurring in Diadema antillarum; but it is clear that he was not aware of the striking manifestation of the phenomenon reported here, which occurs in young forms of this species. Indications of the existence of a rhythmic change in colour persisting under constant external conditions do not appear to have been reported previously in this form, nor indeed, so far as I am aware, in any other echinoderm.

By day, and in strong light, the young Diadema is almost uniformly black (Fig. 1). The spines (which have been cut short so as not to obscure the test) are banded with black and white; but their bases are always blask.

By night, the sides of the test and the spine bases become pale grey, and in parts almost white, while aborally the test develops a strikingly brilliant white pattern in the form of a star around the periproct and enclosing the madreporite, extending into five interambulacral rays which bifurcate toward the ambitus (Fig. 3). Remarkable brilliant blue iridescent colours are to be seen at the edges of the white pattern.

The change from the pale into the dark phase can readily be observed if the animal is placed under a 40-W. lamp, and requires $60-90 \mathrm{~min}$. at $28^{\circ} \mathrm{C}$. for the full range. A narrow beam of light projected on to the test brings about a localized development of the dark colour.

Examination under a low-power binocular shows that these changes are largely due to the dispersion and concentration of melanin in superficial chromatophores ${ }^{3}$. As the pigment disperses, there is not only an overall darkening, but also the white pattern becomes invaded by dispersing pigment, breaking up into isolated portions and eventually disappearing. During this time, the whiteness gives place to lilac and then brilliant blue, so that dispersion of light by melanin may also be involved in the play of colours that ensues.

The phenomenon is independent of the central nervous system or deeply situated nerve elements, since it occurs with equal readiness in small isolated pieces of test which have been scraped clean inside. It therefore appears to be due to the direct action of light on the chromatophores; but the possible existence of a localized superficial skin reflex, or the localized production and action of humoral agents, must be admitted.

Indications of a rhythmic colour change, independ ent of external lighting conditions, can be obtained by keeping an urchin in a light-proof tank. It will be found to darken distinctly during the day, and to assume characteristies intermediate between the pale and dark phases (Fig. 2). Further experiments are required, however, before it can be claimed that the temperature factor has been completely eliminated. Again, this change can be shown to be independent of the central nervous system.

As the young forms age, the colour changes become less striking and may largely disappear - a fact which may be related to the accumulation of melanin in these forms, for the change is still marked in albinotic or partially albinotic forms which are not uncommon in Jamaica. 'There is thus a morphological, as well as a physiological, colour change. 